\title{
石狩川下流部の輸送土砂に関する研究 THE SEDIMENT RUN OFF OF THE ISHIKARI RIVER
}

\author{
渡邊清隆 $1 \cdot$ 清水康行 ${ }^{2} \cdot$ 品川守 $3 \cdot$ 山口甲 4 \\ Kiyotaka WATANABE, Yasuyuki SHIMIZU, Mamoru SHINAGAWA and Hajime YAMAGUTI
1 学生員 北海道大学大学院工学研究科 環境資源工学専攻 （ $\mathrm{T} 060-8628$ 札幌市 北区 北13西8）
2正会員 工博 北海道大学大学院工学研究科 助教授 ( \%060-8628 札幌市 北区 北13西8)
3 正会員 工修 北海道開発局河川管理課長（０600-0000 札幌市 北区 北8西2）
4正会員 工博 北海学園大学工学部教授（０64-0926 札幌市 中央区 南26西11）

\begin{abstract}
It is an important subject to evaluate sediment transport rate in river management works. Especially in a large scale river like Ishikari, establishment of a tool to predict the sediment transport at the estuary is becoming urgent subject from environmental view point. The propose of this paper is to study the effect of the past experienced flood to the grain size distribution of bed material and sediment load. For this propose, data of suspended load observation was collected and the suspended sediment observation was conducted in the Ishikari River. Using these data, and a numerical model, the relationship between suspended sediment load and the discharge history is discussed.
\end{abstract}

Key Words : sediment transport, wash load, numerical model

\section{1.はじめに}

河川の輸送する土砂量の把握は、工学上はもとより 河川環境上も非常に重要な課題である．特に、石狩川 のような大河川の場合には海域に流出する量も非常に 膨大な量となるため、環境問題との関わりも大きく、 愉送土砂量ひ妥当な算定法り碓立が急務となっている。

著者ら ${ }^{1)}$ は石狩川を例に過去 20 年間の水質自動監視 装置による濁度デー夕と流量観測データから石狩川の 濁質から年間総土砂輸送量の算定を行うとともに、石 狩川の河道約 $150 \mathrm{~km}$ の河床変動計算を実施し、wash loadとbed material loadのうちの浮遊砂量との関係に ついて検討を行った。この結果、河口からの流出土砂 量の大部分は非常に微細なwash load成分であることや、 河床変動計算中で発生する浮遊砂のうちの最も微細な 成分の量とwash loadの量がほぼ同じオーダーであるこ となどの興味深い性質が明らかにされた. 即ち、流出 成分の大部分であるwash loadも場合によってはbed material loadと同様に扱うことが可能であるかも知れ ないということであり、これは、流出土砂の予測手法 の開発という立場から見ると非常に好都合なことでも ある. しかしながら、河床変動計算中で発生する浮遊 砂の供給元は河床材料からのみであり、その量はその 時点の河床材料の構成内容に大きく依存する，さらに、
河床材料の構成内容は過去の出水履歴に大きく依存す ることが考えられ、この点を十分に吟味する必要があ る.

本研究においては、この過去の出水履歴と流砂量の関 係に着目して検討を行うものとし、著者ら ${ }^{1)}$ の土砂輸送 モデルでどの程度表現可能かを調べる.

洪水履歴と浮遊砂量の関係を調べるためには、比較的 短期間でひ連続的な実測データとひ比較が重要である ため、1997年の融雪出水時、1997年8月の台風による出 水時、および1998年の融雪出水時に石狩川の石狩大橋 地点および奈井江大橋地点で浮遊砂の連続観測を実施 した。このうち、1997年8月出水時の観測では、約10日 間の間に2回のピークの出水が発生し、この間の浮遊砂 観測に成功している.

そこで、本研究においては特にこの1997年8月の出水 を対象に、対象出水以前の出水履歷が計算される浮遊 砂量に及ぼす影響を数值計算により検討する.

この結果、対象出水以前の出水履歴が、計算される浮 遊砂の量に大きく影響を及ぼすことが明らかにされる。

\section{2. 浮遊砂の観測記録}




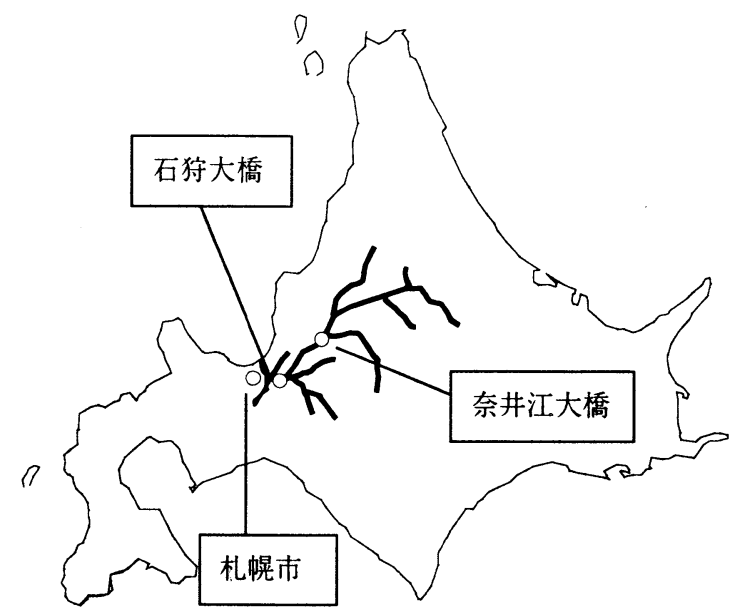

図-1 北海道と石狩川

図-1に示すように石狩川は北海道の北西部に位置し、 全長は268km、流域面積 $14,330 \mathrm{~km}^{2}$ の中には札幌市や旭川 市が含まれている.

石狩川の日本海に面した河口より上流 $26.5 \mathrm{~km} に は$ 全 流域の $90 \%$ を占める石狩大橋(流域面積 $12,697 \mathrm{~km}^{2}$ ) 基準 点がある. 図-2の左方向が下流となっている.

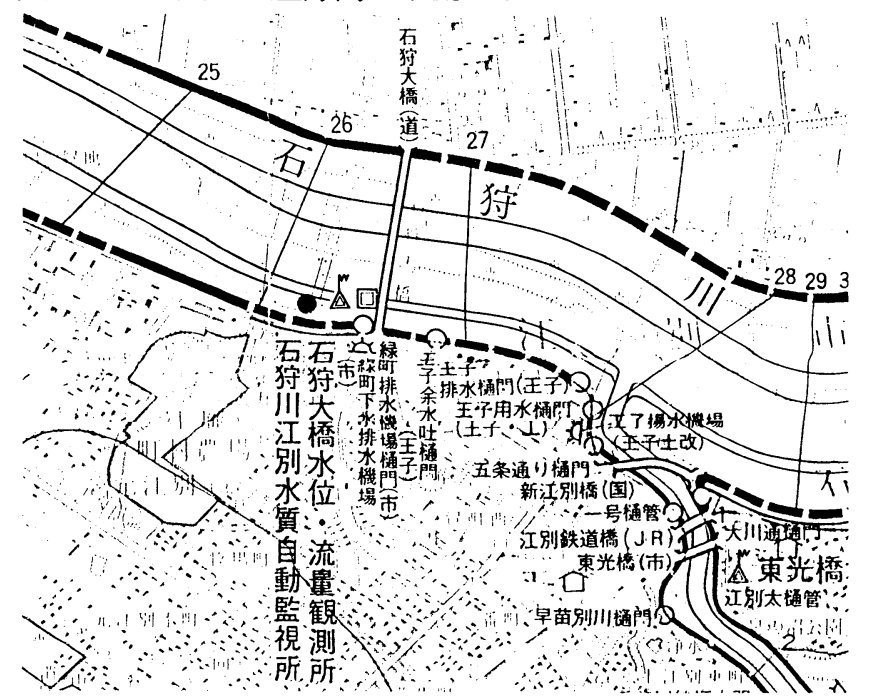

図-2 石狩大橋

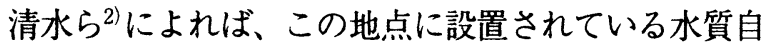
動監視装置により観測された浮遊物質 (SS) は、そのほ とんどが wash loadである.

本研究においては、このSSデータの他に過去におい て石狩川下流部で行われた浮遊砂の観測デー夕を可能 な限り収集・整理を行うとともに、1997年～1998年に かけて実際に石狩川下流部で浮遊砂観測を行い、これ らのデータも検討し使用することとする．なお、実河 川の浮遊砂観測デー夕は公開されたものが非常に少な いため、ここではデー夕公開の重要性も考慮し、可能 な限りのデー夕を以下に数表で示す。但し、流量は水 深からH-Q式を用いて単純に求めたものである。

\section{（1）石狩川下流部の浮遊砂量の実測データ}

1958年から1980年までの間で石狩大橋·篠路鉄橋·河
口橋の3地点において不定期に流量、断面積、水面幅、 総浮遊砂量を観測したものを表-1に示す.

表-1 石狩川下流部の浮遊砂量の実測データ

\begin{tabular}{|c|c|c|c|c|c|}
\hline 観測年月日 & 流量 & 断面皘 & 水面幅 & 総浮遊砂量 & 観測地点 \\
\hline (単位) & $\left(\mathrm{m}^{3} / \mathrm{s}\right)$ & $\left(m^{2}\right)$ & $(m)$ & $\left(\mathrm{m}^{3} / \mathrm{s}\right)$ & \\
\hline 1958. 9.14 & 258 & 556 & 198 & $5.06 \mathrm{E}-03$ & 石狩大畄 \\
\hline 1959.6 .9 & 560 & 644 & 214 & $1.90 \mathrm{E}-02$ & 石狩大楿 \\
\hline 1959.7 .14 & 641 & 743 & 215 & 3.72E-02 & 石狩大楿 \\
\hline 1959.8 .22 & 339 & 599 & 211 & 1.51E-02 & 石狩大橋 \\
\hline 1959.9.21 & 440 & 620 & 211 & $1.53 \mathrm{E}-\mathrm{O} 2$ & 石狩大橋 \\
\hline 1959.11 .5 & 445 & 616 & 212 & $1.46 \mathrm{E}-\mathrm{O} 2$ & 石狩大棈 \\
\hline 1960.6 .8 & 595 & 658 & 215 & $1.51 \mathrm{E}-\mathrm{O} 2$ & 石狩大楅 \\
\hline 1960.7 .15 & 465 & 573 & 188 & 1.05E-01 & 石狩大搳 \\
\hline 1960.8 .6 & 262 & 559 & 194 & $1.11 \mathrm{E}-\mathrm{O} 2$ & 石狩大譛 \\
\hline 1960.10 .1 & 209 & 544 & 199 & $1.18 \mathrm{E}-\mathrm{O} 2$ & 石狩大棈 \\
\hline 1960.10 .21 & 189 & 465 & 168 & $5.13 E-03$ & 石狩大植 \\
\hline 1965.11 .7 & 631 & 1044 & 280 & $3.15 \mathrm{E}-02$ & 萑簬鉄栝 \\
\hline 1965.11 .21 & 1395 & 1364 & 290 & 1.29E-01 & 篗路鉄棈 \\
\hline 1966. 8. 8 & 795 & 1252 & 280 & $1.84 \mathrm{E}-\mathrm{O} 2$ & 䇧路鉄楅 \\
\hline 1966.8 .28 & 1320 & 1320 & 280 & $415 E-02$ & 篗路㪘橸 \\
\hline 1966.9.9 & 981 & 1293 & 280 & $6.25 \mathrm{E}-02$ & 蓝路鉄括 \\
\hline 1966.4 .20 & 818 & 834 & 190 & $4.17 E-02$ & 石狩大標 \\
\hline 1966.4 .21 & 122 & 1011 & 190 & $7.66 \mathrm{E}-03$ & 石狩大栝 \\
\hline 1966.4 .22 & 1391 & 1155 & 190 & 1.05E-01 & 石狩大播 \\
\hline 1966.4 .23 & 1791 & 1252 & 190 & $2.16 \mathrm{E}-01$ & 石狩大抯 \\
\hline 1966.7 .5 & 336 & 579 & 180 & $8.49 \mathrm{E}-03$ & 石狩大括 \\
\hline 1966.7 .6 & 254 & 546 & 180 & $7.14 \mathrm{E}-03$ & 石狩大楅 \\
\hline 1966.8 .17 & 1036 & 944 & 190 & $.05 E-01$ & 太楱 \\
\hline 1966.8 .18 & 1472 & 1160 & 90 & $2.58 E-01$ & 石狩大楿 \\
\hline 1966.10 .4 & 305 & 606 & 180 & $1.06 \mathrm{E}-02$ & 石狩大椱 \\
\hline 1966.10 .5 & 274 & 507 & 180 & $1.14 \mathrm{E}-\mathrm{O} 2$ & 石狩大搕 \\
\hline 1967.7 .18 & 309 & 596 & 180 & $9.55 \mathrm{E}-03$ & 石狩大捂 \\
\hline 1967.8 .31 & 170 & 525 & 180 & $7.58 \mathrm{E}-03$ & 石狩大檑 \\
\hline 1967.9 .1 & 154 & 521 & 180 & $6.26 \mathrm{E}-03$ & 石狩大橋 \\
\hline 1967.10 .18 & 589 & 589 & 180 & $2.50 \mathrm{E}-\mathrm{O} 2$ & 石狩大棈 \\
\hline 1968.7 .7 & 291 & 1055 & 290 & $2.54 \mathrm{E}-\mathrm{O} 2$ & 篌路鉄楅 \\
\hline 1968. 7.20 & 325 & 1022 & 280 & $2.59 \mathrm{E}-\mathrm{O} 2$ & 篗路鉄搳 \\
\hline 1968.8.31 & 430 & 1024 & 280 & $2.13 \mathrm{E}-\mathrm{O} 2$ & 筧䇣路鉄搭 \\
\hline 1968. 9.14 & 345 & 981 & 280 & $1.74 \mathrm{E}-01$ & 篌路鉄橋 \\
\hline 1968.9 .27 & 273 & 911 & 277 & $1.06 \mathrm{E}-02$ & 篻路鉄括 \\
\hline $1968 \cdot 9.30$ & 405 & 1070 & 280 & $1.56 \mathrm{E}-\mathrm{O} 2$ & 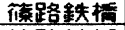 \\
\hline 1968.10 .19 & 323 & 993 & 280 & $2.17 \mathrm{E}-\mathrm{O} 2$ & 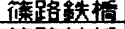 \\
\hline 1968.10 .24 & 305 & 976 & 280 & $2.44 \mathrm{E}-02$ & 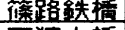 \\
\hline 1968.7.13 & 180 & 552 & 190 & $9.39 \mathrm{E}-03$ & 石狩大稩 \\
\hline 1968.9 .8 & 441 & 608 & 190 & $65 \mathrm{E}-02$ & 石狩太榃 \\
\hline 1968.9.22 & 911 & 778 & 200 & 1.67E-01 & 石狩大榙 \\
\hline 1968.9 .27 & 282 & 538 & 190 & $1.33 \mathrm{E}-02$ & 五狩太椾 \\
\hline 1968.9.30 & 282 & 553 & 190 & 1.20E-02 & 石狩大情 \\
\hline 1968.10 .19 & 264 & 553 & 190 & -02 & 石狩大栝 \\
\hline 1968.10 .19 & 272 & 538 & 190 & $\mathrm{E}-\mathrm{O} 2$ & 大楿 \\
\hline 1968.10 .21 & 260 & 519 & 190 & $3.52 \mathrm{E}-\mathrm{O} 2$ & 石狩大橙 \\
\hline 1968.10 .21 & 260 & 519 & 190 & $1.09 \mathrm{E}-02$ & 石狩大檻 \\
\hline 1969.4 .14 & 2024 & 1252 & 220 & 1.11E-01 & 石狩大橧 \\
\hline 1969.4 .15 & 1942 & 1268 & 220 & $8.18 \mathrm{E}-02$ & 石狩大㿾 \\
\hline 1969.4 .18 & 1192 & 1036 & 218 & $7.62 \mathrm{E}-\mathrm{O} 2$ & 石狩大檑 \\
\hline 1969.4 .21 & 1799 & 1068 & 218 & $1.06 \mathrm{E}-01$ & 石狩大棈 \\
\hline 1969.5 .13 & 796 & 787 & 216 & $25 \mathrm{E}-02$ & 石狩大棈 \\
\hline 1969.7 .9 & 120 & 475 & 170 & -03 & 石狩大垫 \\
\hline 1969.7 .22 & 239 & 502 & 14 & $\mathrm{E}-\mathrm{O} 2$ & 大梧 \\
\hline 1969.8 .29 & 1492 & 937 & 220 & $2.58 \mathrm{E}-01$ & 石狩大橋 \\
\hline 1979.5. 2 & 1207 & 1631 & 278 & $4.97 \mathrm{E}-02$ & 河口橋 \\
\hline 1979.5. 9 & 1483 & 1650 & 281 & 1.58E-01 & 河口撩 \\
\hline 1979.6.12 & 1691 & 1691 & 283 & 2.62E-O1 & 河口椣 \\
\hline 1979.10 .3 & 1202 & 1658 & 263 & $1.32 \mathrm{E}-01$ & 河口整 \\
\hline 1979.10 .20 & 3965 & 2286 & 290 & $.02 \mathrm{E}+00$ & 河口楿 \\
\hline 1979.10 .20 & 4281 & 2317 & 291 & $2 E+\infty 0$ & 河口橋 \\
\hline 1980.11 .2 & 1291 & 1707 & 84 & $1 \mathrm{E}-01$ & 河口棈 \\
\hline 1980.11 .15 & 1322 & 1658 & 281 & 8.30E-02 & 河口盖 \\
\hline 1980.12 .5 & 982 & 1644 & 279 & $2.90 E-02$ & 河口棈 \\
\hline 1980.12 .5 & 957 & 1546 & 279 & $2.37 \mathrm{E}-02$ & 河口橋 \\
\hline 1981.4 .28 & 2211 & 1715 & 260 & 1.17E-01 & 河口唃 \\
\hline 1981.5 .3 & 2475 & 1736 & 260 & $1.72 \mathrm{E}-01$ & 河口椿 \\
\hline 1981.8 .6 & 10904 & 2452 & 260 & $6.05 E+00$ & 河口椿 \\
\hline 1981.8 .6 & 9869 & 2445 & 260 & $5.39 E+00$ & 河口標 \\
\hline 1981.8 .8 & 3470 & 2635 & 260 & $5.72 \mathrm{E}-01$ & 河口筒 \\
\hline 1981.8 .8 & 3609 & 2662 & 260 & $5.94 \mathrm{E}-01$ & 河口啝 \\
\hline 1981.8 .9 & 2606 & 1468 & 256 & 1.85E-01 & 箎路鉄栝 \\
\hline 1981.8 .11 & 1320 & 1100 & 252 & $4.03 E-02$ & 篗路鉄俩 \\
\hline 1981.9 .5 & 3039 & 1802 & 257 & $6.29 \mathrm{E}-01$ & 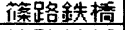 \\
\hline 1981.9 .5 & 2975 & 1796 & 256 & $5.60 \mathrm{E}-01$ & 钞路鉄橋 \\
\hline 1987.4 .23 & 4232 & 2385 & 439 & 8.79E-01 & 箖路鉄橋 \\
\hline 1987.4 .23 & 4206 & 2339 & 377 & $6.64 \mathrm{E}-01$ & 札幌大楅 \\
\hline 1987.8 .27 & 2016 & 1876 & 351 & $1.81 \mathrm{E}-01$ & 札幌大慻 \\
\hline 1987.8 .27 & 1966 & 1870 & 351 & $1.64 \mathrm{E}-01$ & 札幌大潜 \\
\hline 1987.8 .27 & 1921 & 1876 & 351 & $1.40 \mathrm{E}-01$ & 札幌大標 \\
\hline 1987.8 .27 & 1968 & 1881 & 351 & $1.30 \mathrm{E}-01$ & 札幌大楅 \\
\hline
\end{tabular}


（2）石狩川浮遊砂観則データ (1997年) ${ }^{3)}$

1997年春の融雪期 $(4 、 5$ 月) と 8 月の出水時に、石狩大 橋·奈井江大橋·伊納大橋の石狩川本流3箇所と、裏の沢 (千歳川) ·雁来 (豊平川) ·清幌橋 (夕張川)の3個所の、計 6箇所で流量、浮遊砂量、掃流砂量、水質、及び河床材 料の調査を行ったうちの、石狩大橋のもの表-2に示す. ここでは左岸より $285 \mathrm{~m}$ の地点で表層採水を行っている.

表-2 石狩川浮遊砂観測データ(1997年)

\begin{tabular}{|c|c|c|c|c|}
\hline $\begin{array}{l}\text { 鿷測年月日 } \\
\end{array}$ & No. & 全水深 & 流量 & SS \\
\hline (単位) & & (m) & $\left(\mathrm{m}^{3} / \mathrm{s}\right)$ & $\left(\mathrm{m}^{3} / \mathrm{s}\right)$ \\
\hline 1997.4 .25 & 1 & 4.33 & 756 & 24 \\
\hline 997.4 .29 & 2 & 5.75 & 1629 & 277 \\
\hline 997.5 .2 & 3 & 4.90 & 1111 & 90 \\
\hline 1997.5. 6 & 4 & 5.08 & 1317 & 106 \\
\hline 1997.5 .9 & 5 & 5.54 & 1700 & 251 \\
\hline 1997.5 .14 & 6 & 4.57 & 891 & 56 \\
\hline 1997 & 7 & 57 & 96 & 140 \\
\hline 1997 & 8 & 73 & 95 & 156 \\
\hline 1997. & $y$ & 76 & 644 & 136 \\
\hline 1997.5 .17 & 10 & 5.80 & 1644 & 135 \\
\hline 997.5 .20 & 11 & 4.81 & 955 & 60 \\
\hline 1997.5 .21 & 12 & 4.70 & 916 & 69 \\
\hline 1997.8 .5 & 13 & 5.10 & 1334 & 112 \\
\hline 1997.8 .5 & 14 & 4.84 & 1160 & 81 \\
\hline 1997.8 .6 & 15 & 4.91 & 1206 & 349 \\
\hline 1997.8 .6 & 16 & 5.06 & 1306 & 344 \\
\hline 1997.8 .6 & 17 & 5.17 & 1382 & 320 \\
\hline 1997.8 .6 & 18 & 5.16 & 1578 & 276 \\
\hline 1997.8 .6 & 19 & 5.07 & 1350 & 215 \\
\hline 1997.8 .7 & 20 & 4.35 & 542 & 92 \\
\hline 1997.8 .7 & 20 & 4.35 & 542 & 93 \\
\hline 1997.8 .7 & 20 & 4.35 & 542 & 104 \\
\hline 1997.8 .7 & 20 & 4.35 & 542 & 127 \\
\hline 1997.8 .10 & 21 & 6.05 & 2065 & 375 \\
\hline 1997.8 .10 & 22 & 6.50 & 2488 & 580 \\
\hline 1997.8 .10 & 23 & 6.85 & 2838 & 940 \\
\hline 1997.8 .10 & 24 & 7.10 & 3074 & 1150 \\
\hline 1997.8 .10 & 25 & 7.25 & 3218 & 1200 \\
\hline 1997.8 .11 & 26 & 6.90 & 2733 & 892 \\
\hline 1997.8 .11 & 27 & 6.35 & 2367 & 548 \\
\hline
\end{tabular}

(3) 石狩川浮遊砂観測データ (1998年)

遊砂調査、水質調査を横断方向と鉛直方向にそれぞれ 行ったものを表-3に示す。なお、1998年の観測は1997 年の観測に比べて採集日数は少ないが横断方向や鉛直 方向にも採取位置を増やし、図-3に示す断面内で多点 観測を行ったものである．黑丸は調査位置を示す。

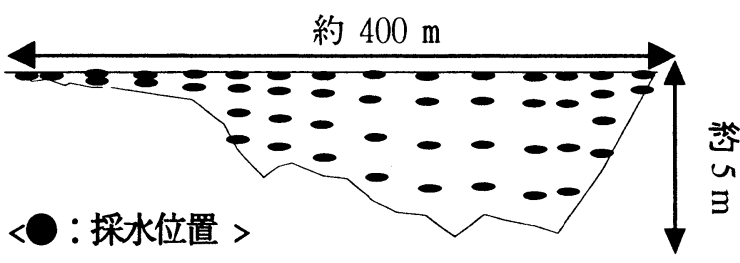

図-3 1998年石狩大橋における浮遊砂観則の採水位置
表-3 石狩川浮遊砂観測データ(1998年)

\begin{tabular}{|l|l|l|l|l|l|}
\hline 観測年月日 & 水位 & 流量 & SS & 採水位置 & 採水水深 \\
\hline
\end{tabular} \begin{tabular}{|c|c|c|c|c|c|}
\hline (果位 $)$ & $(\mathrm{m})$ & $\left(\mathrm{m}^{3} / \mathrm{s}\right)$ & $(\mathrm{mg} / \mathrm{l})$ & 左岸より $(\mathrm{m})$ & $(\mathrm{m})$ \\
\hline 1
\end{tabular}

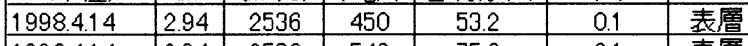
\begin{tabular}{|l|l|l|l|l|l|l}
\hline 1998.4 .14 & 2.94 & 2536 & 540 & 75.0 & 0.1 & 表層 \\
\hline
\end{tabular}

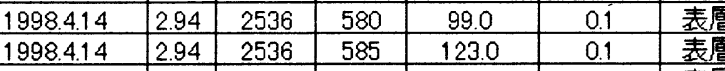

\begin{tabular}{|c|c|c|c|c|c|c|}
\hline 1998.4 .14 & 2.94 & 2536 & 600 & 150.0 & 0.1 & 表 \\
\hline 1998.4 .14 & 2.94 & 2536 & 605 & 180.0 & 0.1 & 吾 \\
\hline
\end{tabular}

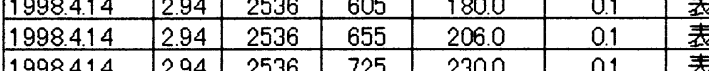

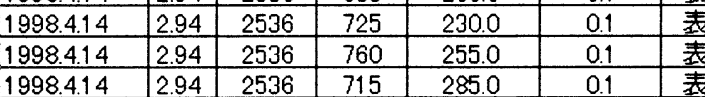

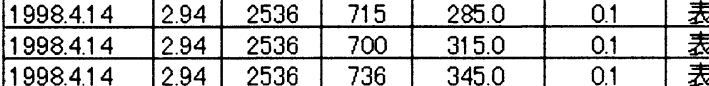
\begin{tabular}{|l|l|l|l|l|l|l|}
\hline 1998.4 .14 & 2.94 & 2536 & 736 & 345.0 & 0.1 & 表 \\
\hline 1998.4 .14 & 2.94 & 2536 & 755 & 375.0 & 0.1 & 表 \\
\hline 1998.414 & 294 & 2536 & 700 & 393. & 0.1 &
\end{tabular} \begin{tabular}{|l|l|l|l|l|l|l|}
\hline 1998.4 .14 & 2.94 & 2536 & 700 & 393.7 & 0.1 & 表 \\
\hline 1998.414 & 2.94 & 2536 & 700 & 415.0 & 0.1 & 表 \\
\hline
\end{tabular}

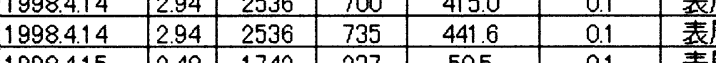
\begin{tabular}{|l|l|l|l|l|l|l|}
\hline 1998.4 .15 & 2.48 & 1742 & 237 & 50.5 & 0.1 & 表 \\
\hline 1998.4 .15 & 2.48 & 1742 & 258 & 75.0 & 0.1 & 表
\end{tabular}

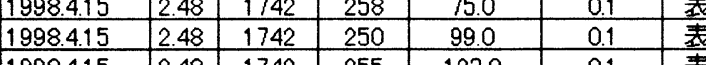
\begin{tabular}{|l|l|l|l|l|l|l|}
\hline 1998.4 .15 & 2.48 & 1742 & 255 & 123.0 & 0.1 & 表 \\
\hline 1998.4 .15 & 2.48 & 1742 & 275 & 150.0 & 0.1 & 袁 \\
\hline
\end{tabular}

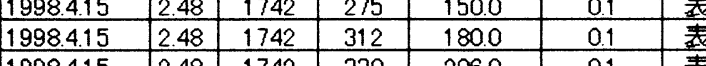
\begin{tabular}{|l|l|l|l|l|l|l|}
\hline 1998.4 .15 & 2.48 & 1742 & 330 & 206.0 & 0.1 & 袁 \\
\hline 1998.4 .15 & 2.48 & 1742 & 342 & 230.0 & 0.1 & 表 \\
\hline
\end{tabular} \begin{tabular}{|l|l|l|l|l|l|l|}
\hline 1998.4 .15 & 2.48 & 1742 & 342 & 230.0 & 0.1 & 表 \\
\hline 1998.4 .15 & 2.48 & 1742 & 318 & 255.0 & 0.1 & 表 \\
\hline 1998.45 & 2.48 & 1742 & 332 & 285.0 & 01 &
\end{tabular} \begin{tabular}{|l|l|l|l|l|l|l|}
\hline 1998.4 .15 & 2.48 & 1742 & 332 & 285.0 & 0.1 & 表 \\
\hline 1998.4 .15 & 2.48 & 1742 & 348 & 315.0 & 0.1 & 表
\end{tabular}

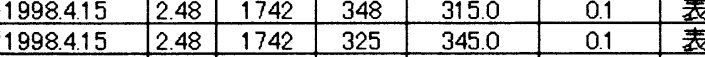

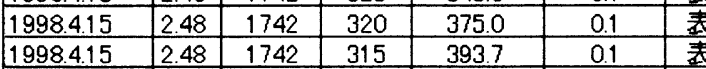

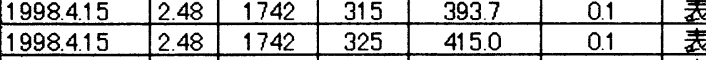

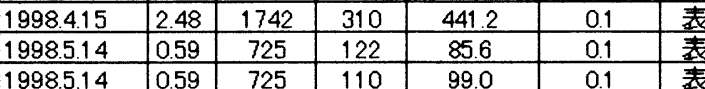
\begin{tabular}{|c|c|c|c|c|c|c|}
\hline 1998.5 .14 & 0.59 & 725 & 110 & 99.0 & 0.1 & 表 \\
\hline 1998.5 .14 & 0.59 & 725 & 110 & 123.0 & 0.1 & 表
\end{tabular}

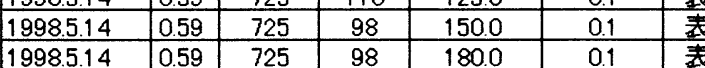
\begin{tabular}{|l|c|c|c|c|c|c|}
\hline 1998.5 .14 & 0.59 & 725 & 98 & 180.0 & 0.1 & 表 \\
\hline 1998.5 .14 & 0.59 & 725 & 100 & 206.0 & 0.1 & 䘚 \\
\hline
\end{tabular} \begin{tabular}{|l|l|l|l|l|l|l|}
\hline 1998.5 .14 & 0.59 & 725 & 112 & 230.0 & 0.1 & 袁 \\
\hline 1998.5 .14 & 0.59 & 725 & 126 & 255.0 & 0.1 & 表
\end{tabular} \begin{tabular}{|l|l|l|l|l|l|l|}
\hline 1998.5 .14 & 0.59 & 725 & 134 & 285.0 & 0.1 & 䘚 \\
\hline 19985.14 & 0.59 & 725 & 142 & 3150 & 0.1 &
\end{tabular}

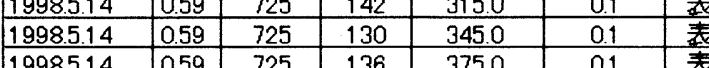

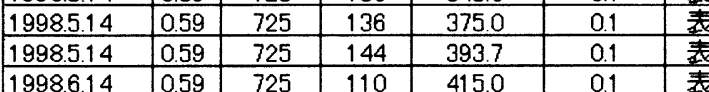

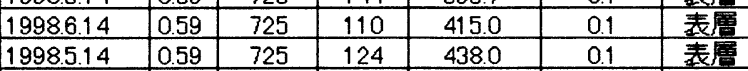
\begin{tabular}{|l|c|c|c|c|c|c|}
\hline 1998.5 .14 & 0.59 & 725 & 96 & 206.0 & 0.5 & 2割 \\
\hline 1998.5 .14 & 0.59 & 725 & 118 & 230.0 & 0.6 & 2割 \\
\hline
\end{tabular}

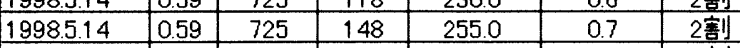
\begin{tabular}{|l|l|l|l|l|l|l|}
\hline 1998.5 .14 & 0.59 & 725 & 182 & 285.0 & 0.8 & 2 割 \\
\hline 1998.5 .14 & 0.59 & 725 & 150 & 315.0 & 0.9 & 2 2割 \\
\hline
\end{tabular} \begin{tabular}{|l|l|l|l|l|l|l|}
\hline 1998.5 .14 & 0.59 & 725 & 168 & 345.0 & 0.9 & 2 割 \\
\hline
\end{tabular} \begin{tabular}{|l|l|l|l|l|l|l|}
\hline 1998.5 .14 & 0.59 & 725 & 140 & 375.0 & 1 & 2 割 \\
\hline 1998.14 & 0.59 & 725 & 126 & 393.7 & 1 & 2 割 \\
\hline
\end{tabular} \begin{tabular}{|l|l|l|l|l|c|c|}
\hline 1998.5 .14 & 0.59 & 725 & 126 & 393.7 & 1 & 2 割 \\
\hline 1998.5 .14 & 0.59 & 725 & 142 & 415.0 & 0.6 & 2割 \\
\hline
\end{tabular} \begin{tabular}{|l|l|l|l|l|l|l|}
\hline 1998.5 .14 & 0.59 & 725 & 112 & 123.0 & 0.3 & 5 割 \\
\hline 1998.5 .14 & 0.59 & 725 & 102 & 150.0 & 0.3 & 5 割 \\
\hline
\end{tabular} \begin{tabular}{|l|l|l|l|l|l|l|}
\hline 1998.5 .14 & 0.59 & 725 & 152 & 180.0 & 0.5 & 5 割 \\
\hline 19985.44
\end{tabular} \begin{tabular}{|l|l|l|l|l|l|l|}
\hline 1998.5 .14 & 0.59 & 725 & 108 & 206.0 & 1.3 & 5 割 \\
\hline 1998.5 .14 & 0.59 & 725 & 130 & 230.0 & 1.5 & 5 割 \\
\hline 1998.54 & 0.59 & 725 & 142 & 255.0 & 1.7 & 5 剽 \\
\hline
\end{tabular} \begin{tabular}{|l|l|l|l|l|l|l|}
\hline 1998.5 .14 & 0.59 & 725 & 142 & 255.0 & 1.7 & 5 割 \\
\hline 1998.14 & 0.59 & 725 & 166 & 285.0 & 2.1 & 5 \\
\hline
\end{tabular} \begin{tabular}{|l|l|l|l|l|l|l|}
\hline 1998.5 .14 & 0.59 & 725 & 166 & 285.0 & 2.1 & 5 割 \\
\hline 1998.5 .14 & 0.59 & 725 & 158 & 315.0 & 2.3 & 5 割 \\
\hline 19985.34 & 0.59 & 725 & 178 & 345.0 & 2.3 & 5 剖 \\
\hline
\end{tabular} \begin{tabular}{|l|l|l|l|l|l|l|}
\hline 1998.5 .14 & 0.59 & 725 & 178 & 345.0 & 2.3 & 5 割 \\
\hline
\end{tabular} \begin{tabular}{|l|l|l|l|l|l|l|}
\hline 1998.5 .14 & 0.59 & 725 & 160 & 375.0 & 2.5 & 5 割 \\
\hline 1998.5 .14 & 0.59 & 725 & 140 & 393.7 & 2.4 & 5 割 \\
\hline
\end{tabular} \begin{tabular}{|l|l|l|l|l|l|l|}
\hline 1998.5 .14 & 0.59 & 725 & 140 & 393.7 & 2.4 & 5 割 \\
\hline 1998.5 .14 & 0.59 & 725 & 128 & 415.0 & 1.6 & 5 割 \\
\hline
\end{tabular} \begin{tabular}{|l|l|l|l|l|l|l|}
\hline 1998.5 .14 & 0.59 & 725 & 166 & 438.0 & 0.4 & 5 割 \\
\hline 1998.14 & 0.59 & 725 & 323 & 206.0 & 2.1 & 8 割 \\
\hline
\end{tabular} \begin{tabular}{|l|l|l|l|l|l|l|}
1998.5 .14 & 0.59 & 725 & 323 & 206.0 & 2.1 & 8 割 \\
\hline 1998.5 .14 & 0.59 & 725 & 118 & 230.0 & 2.4 & 8 割 \\
\hline
\end{tabular} \begin{tabular}{|l|l|l|l|l|l|l|}
\hline 1998.5 .14 & 0.59 & 725 & 138 & 255.0 & 2.7 & 8 割 \\
\hline
\end{tabular} \begin{tabular}{|l|l|l|l|l|l|l|}
1998.5 .14 & 0.59 & 725 & 154 & 285.0 & 3.4 & 8 割 \\
\hline 19985.14 & 0.59 & 725 & 148 & 315.0 & 37 & 8 割 \\
\hline
\end{tabular} \begin{tabular}{|l|l|l|l|l|l|l|}
\hline 1998.5 .14 & 0.59 & 725 & 148 & 315.0 & 3.7 & 8 割 \\
\hline
\end{tabular} \begin{tabular}{|l|l|l|l|l|l|l|}
1998.5 .14 & 0.59 & 725 & 160 & 345.0 & 3.7 & 8 割 \\
\hline 1998.5 .14 & 0.59 & 725 & 170 & 375.0 & 4 & 8 割 \\
\hline
\end{tabular} \begin{tabular}{|l|l|l|l|l|l|l|}
\hline 1998.5 .14 & 0.59 & 725 & 170 & 375.0 & 4 & 8 割 \\
\hline 1998.14 & 0.59 & 725 & 132 & 393.7 & 3.8 & 8 割 \\
\hline
\end{tabular} \begin{tabular}{|l|l|l|l|l|l|l|}
\hline 1998.5 .14 & 0.59 & 725 & 140 & 415.0 & 2.6 & 8 割 \\
\hline
\end{tabular} 
図-4は本文中に載せた資料(1)～(3)の浮遊砂量の内、 石狩大橋における流量と浮遊砂量の関係を示す。ここ で、観測データが濃度の形で整理されているデー夕は 土粒子の密度を $\rho_{\mathrm{s}}=2.65\left[\mathrm{ton} / \mathrm{m}^{3}\right]$ として、各観測時点の 流量を用いて浮遊砂量に換算してある。なお、図-4中 の実線は全データによる流量と浮遊砂量の相関式であ る.また図-4中の破線は清水ら゙による過去20年間の石 狩大橋地点の日流量と濁度データの解析により得られ た相関式である。

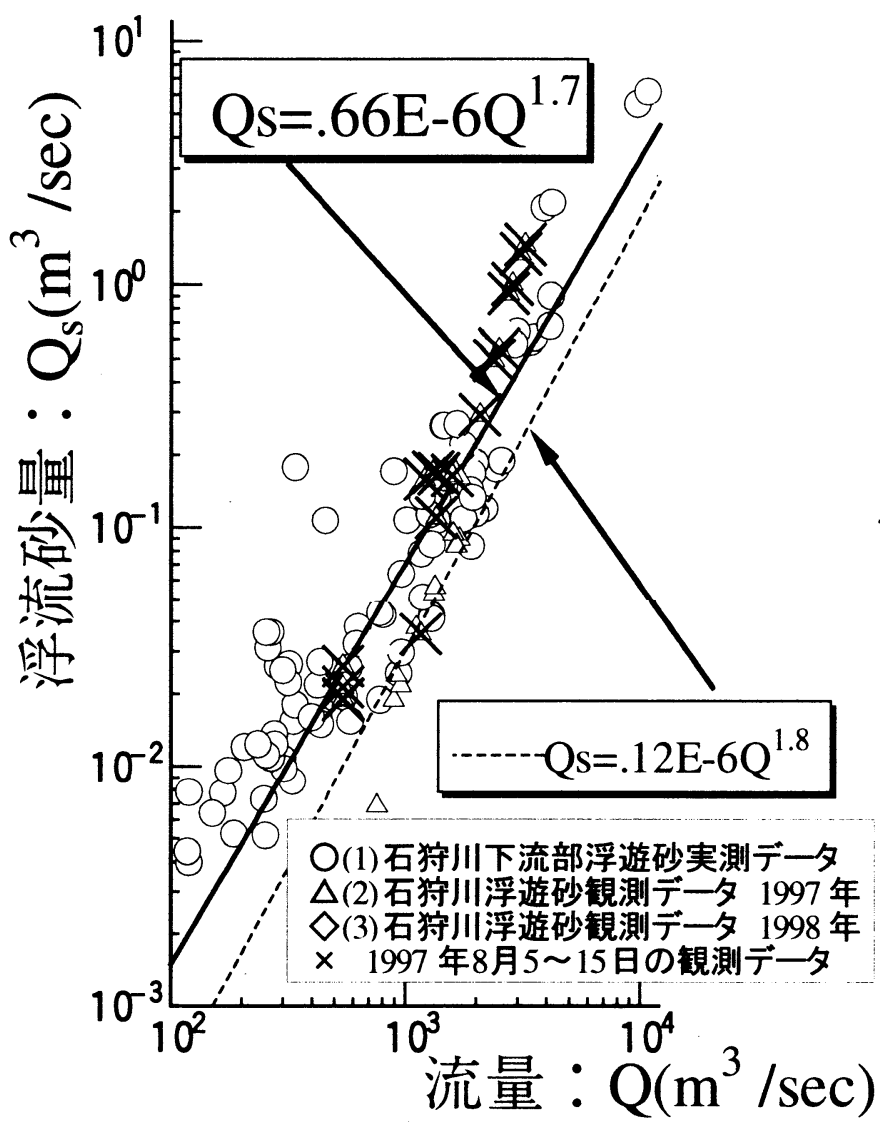

図-4 石狩川下流部における流量と浮遊砂量の関係

石狩川下流部での浮遊砂量は、おおよそ流量の1.7乗 に比例する事を示している。ここでのデータはすべて 観測時点の瞬間值であり日平均デー夕に基づくものに 比べてその量は多い傾向が見られる。

\section{3. 出水時の浮遊砂量の算定法}

出水中のハイドログラフの各瞬間における浮遊砂量 算定の可能性を検討する目的で、一連の出水中に河床 から発生して河川に沿って輸送される浮遊砂量を計算 する. 対象とする出水は、図-5に示すように、1997年 夏の $8 / 5$ - 8/15までの、2つの流量ピークを持つ出水と する．図-5の水位 (実線) と流量 (点線)は石狩大橋で観 測されたものであり、1回目の流量ピークは8月6日で、 約 $1500 \mathrm{~m}^{3} / \mathrm{sec}$ 、2回目の流量ピークはその 4 日後の 8 月 10
日梁夜で、約 $350 \mathrm{~m}^{3} / \mathrm{sec}$ とっている，図-5中の黒丸は、 この時点で採水が行われたことを示している.

この期間に行われた観測回数は13回で、観測記録は (2) 石狩川浮遊砂観測デー夕 (表-2)のNo. 14〜27である. 図-4中にあるメ印は、この時の流量と浮遊砂量の関係 である。

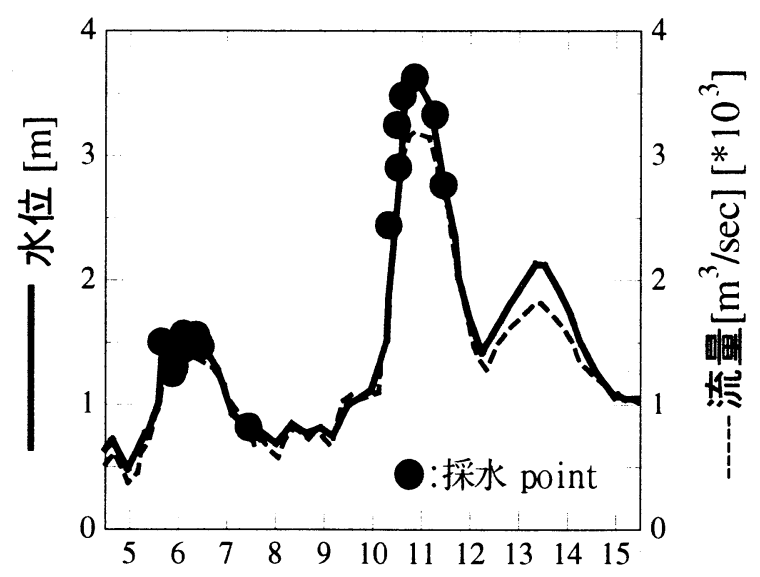

1997 年8月の日付

図-5 石狩大橋における1997年8月出水時の水位・流量 の時刻変化

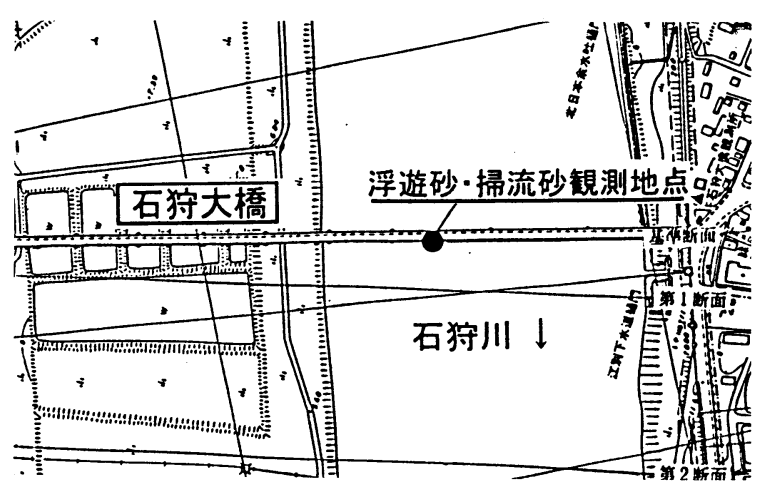

図-6 1997年8月 石狩大橋における採水地点

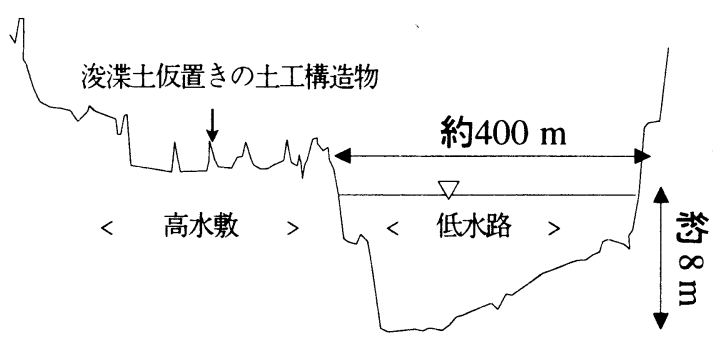

図-7 石狩大橋地点の断面と出水時の水面形

採水地点は図-6に示す石狩大橋 (上が上流)の黒丸地点 (左岸から $285 \mathrm{~m}$ ) である. 図-7は採水時の石狩大橋地点 の断面図であり、図中の水面はピーク時 (流量約 $3,300 \mathrm{~m}^{3} / \mathrm{sec}$, 水位 $\left.3.6 \mathrm{~m}\right)$ を表している.

河床材料から発生して河道内を移流・拡散する浮遊砂 量を、著者らの一人による石狩川の河床変動計算モデル 6! を用いて算定する。ここでは、石狩大橋地点において 流砂の大部分である浮遊砂についてのみ比較する。なお、 モデルでは wash load も最小粒径の浮遊砂としてbed 
material $\operatorname{load}$ と同様に浮上(再浮上) - 沈降 ・移流・拡 散も考慮されたものとなっている．モデルに関する詳細 は省略1するが、その概要は以下のとおりである.

（a）計算区間：石狩川の河口から $125 \mathrm{~km}$ の区間.

（b）基礎式：1 次元不等流、粒径別掃流砂·浮流砂量式、 粒径別濃度連続式、粒径別流砂連続式、全流砂の 連続式.

（c）境界条件：上流端で流砂の動的平衡状態（その場の 掃流力から計算される流砂量を与える）支川から の流入土砂も動的平衡条件、下流端水位は潮位の 奏測値、卜流端の流砂量は自由流出。

（d）初期河床縦断形状：実測デー夕をから作った近似式 により、河口からの距離 $k_{p}(\mathrm{~km})$ の関数として河床 高 $\eta(\mathrm{m})$ を次式で与える.

$$
\eta=4.764 \exp \left(0.0192 k_{p}\right)-10.0
$$

（e）河床材料の初期粒径分布：過去の実測資料より得ら れた近似式を用いて $\mathrm{d}_{10}, \mathrm{~d}_{50}$ および $\mathrm{d}_{90}$ をちえる。縦断 図中の各地点の粒度分布は対数正規分布に従うも のとする.ここで、 $\mathrm{d}_{10}, \mathrm{~d}_{50}$ および $\mathrm{d}_{90}$ はそれぞれ $10 \%$, 50\% および90\%粒径(単位m)である.

$$
\begin{aligned}
& d_{10}=0.141 \exp \left(0.0174 k_{p}\right) \\
& d_{50}=0.240 \exp \left(0.0359 k_{p}\right) \\
& d_{90}=0.831 \exp \left(0.0359 k_{p}\right)
\end{aligned}
$$

（f）河床材料の粒径：表-4に示すように10のクラスに分 割しそれぞれの代表粒径を表に示すように与える。 表-4 河床変動計算における河床材料の分割法 分割クラス

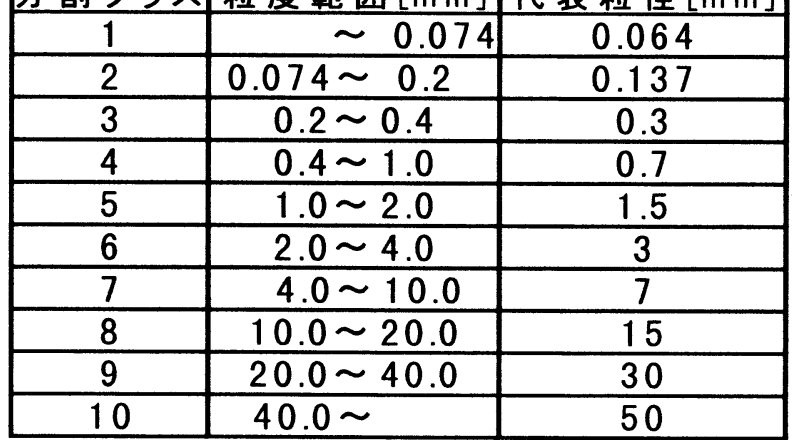

（g）流量：下流端流量は、石狩大橋とその下流支川の主 要支川である豊平川の時刻流量を与え、上流に向 かって流入支川の影響を考慮して徐々に減少する 分布形を与える。

\section{4. 計算結果}

\section{（1）短期間の出水における浮遊砂量}

初期条件として与えた粒度分布及び河床高を用いて、 図-5に示す10日間の時刻流量を逐次与え、求まった浮 遊砂濃度を図-10に点線で示した. 図-10によれば、最初
のピークでは、計算による浮遊砂濃度が実測值よりも 一桁ほど大きく算出されていることが分かる.次の流量 のピークは前のピークの約 2 倍であるが、計算結果の 浮遊砂は、はじめのピークほど顕著に発生していない.

（2）出水履歴を伴う短期間の出水における浮遊砂量

次に対象としている出水期間だけの数值計算をする のではなく、図-8に示すようにあらかじめ出水以前の ある期間(ここでは試行的に1年とした)の計算を行う.

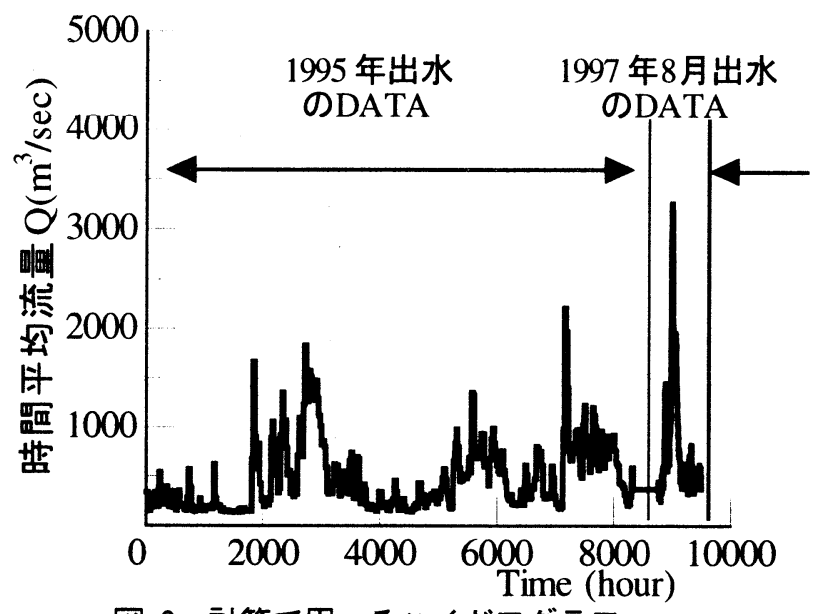

図-8＼cjkstart計算で用いるハイドログラフ
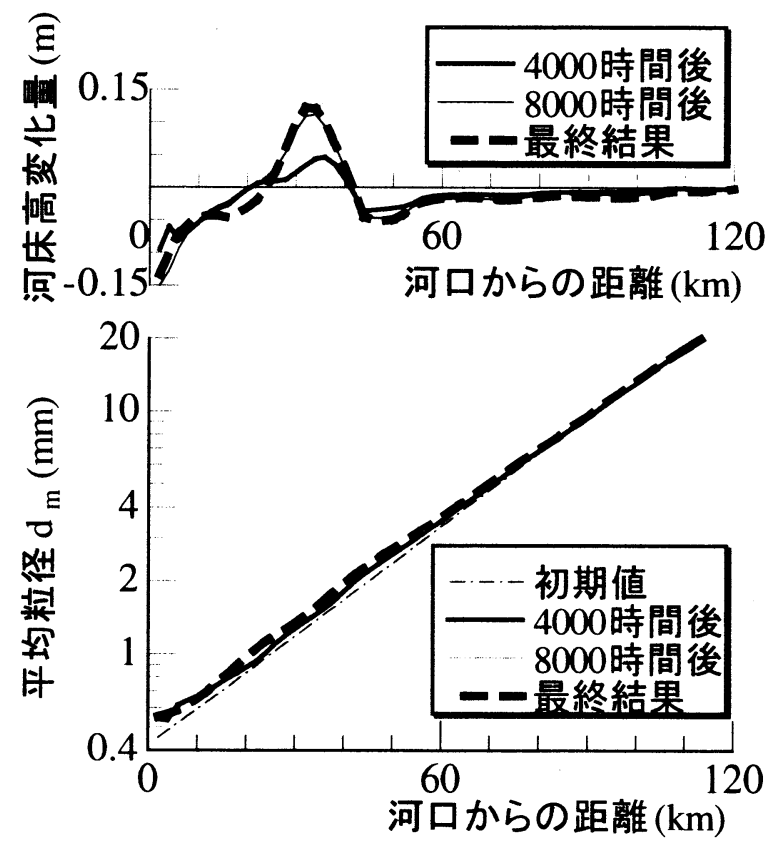

図-9 出水経験後(1年間)の河床材料と標高の変化

図-9に1年間出水を経験させた後の河床変動および河床 材料の粒度変化を示す(記入されている時間は図-8の時 間と対応している)。図-9によれば、石狩大橋上流部 （30～40kp区間）においては常に堆積しており、8000時 間で河床は約 $12 \mathrm{~cm}$ 上昇している.1997年8月の出水の計 算後と比較すると、この部分の河床高の変化はほとん どないが、20kpから下流部で河床が低下したことが分 かる.河口より60kp付近までは平均粒径が僅かながら大 きくなっていることから、石狩大橋上流部(30４0kp区 間)においては、上流より運ばれてきた粗い砂がこの部 


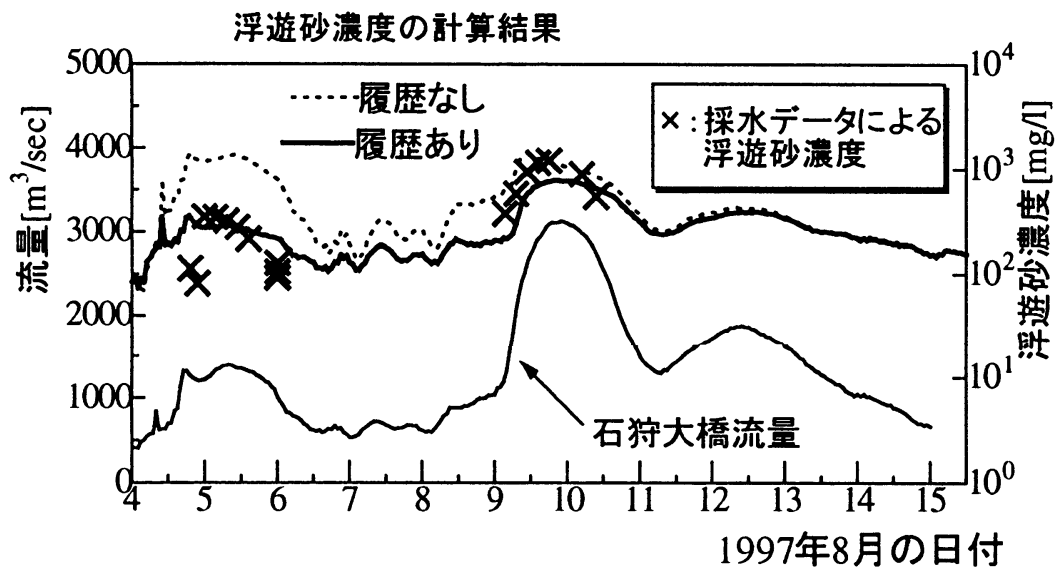

図-10

出水履歴がある時と

無いときの浮遊砂

濃度の違い

分で堆積したと考えられる。この後に1997年8月の出水 期間の条件を与え浮遊砂濃度を求めた。 その結果を図10に実線で示す．図-10によれば、最初のピークでは、 計算結果は実測の浮遊砂濃度とほほ一致している．2つ めのピークでは、最も流量が多いときの計算濃度が実 測值を下回る結果となっているが、流量が大きい出水 のほうが、浮遊砂濃度も大きいという特性を良く表現 している. 今回は試行的にある特定の 1 年分の出水履 歴を与えたが、この結果石狩大橋地点 $(26 \mathrm{kp})$ では履歴 計算中に若干の河床上昇と河床材料の粗粒化が、上流 部分 (30 40kp) では堆積と粗粒化が、さらに上流部分 （40kp以降）では河床低下と若干の粗粒化が計算された。 過去の履歴により、河床中の非常に細かい粒子は流出 してしまい、8月出水の 1 つめのピークでは上流部の河 床から浮上した浮遊砂が、履歴計算を行わない場合に 比べ実測に近い值となったと考えられる，一方、2つ めのピークに関しては 1 つめのピークがある程度出水 履歴の役割を果たしたことと、 $3,000 \mathrm{~m}^{3} / \mathrm{sec}$ という数年 に一度の比較的大きな出水であったため、もともと河 床にあった材料が再浮上し、計算結果に大きな違いが 現れなかったと考えられる。なお、今回示した計算例 の他に様々なパターンの出水履歴と浮遊砂濃度の計算 を行ったが、現時点でははっきりとした特性(例えば履 歴の規模、パターン、期間と土砂流出特性の関係)を明 言出来るには至っていない.

\section{5. 考察}

本研究においてはまず、石狩川の過去における浮遊砂 実測デー夕、および 2 年間にわたる融雪時および夏季 出水時の連続観測デー夕を整理し、デー夕の重要性を 考慮して全データの数表による公開を行った。これら の瞬間的なデータと以前に行われた日平均デー夕に基 づく資料の比較を行った結果、その違いが明らかにさ れた。ささらに特定の出水に着目して連続的な浮遊砂量 の計算による再現を試みた結果、計算においても過去 流量履歴により計算結果が大きく異なることが明らか
にされた，即ち、過去の出水を経験させてから対象と なる出水期間の浮遊砂濃度を計算したほうがより実際 の現象に近い結果となった，ある意味では当然の結果 ではあるが、短期間の出水で発生する浮遊砂量を数值 計算で求めるときは、計算対象期間だけの流量を与え て浮遊砂量を求めるのではなくある程度の期間、実際 の流量を与えて河床変動及び河床材料の粒径の変化を 経験させた後に、対象となる出水期間の数值計算を 行ったほうが実際の現象と近い結果が得られるという ことである.実際に経験した流量を与えた後に計算を行 うという操作は、初期条件として与えた河床材料の性 質や河床高等の条件を、出水時期直前の状態に近づけ るための操作となっていると考えられる、極端に言えば、 河床高や河床材料の粒径分布の初期条件が多少現実と 異なっていても、過去の出水を経験させれば、実際の 現象に近い結果が得られる可能性を示すものである.

出水時期直前の厳密な河床材料の粒径分布や河床高の 情報を得ることは極めて困難であり、これに対して基 準点の水位や流量といった基本的な情報が存在すれば、 短期間出水に扔ける浮遊砂量をある程度の精度で予測 することが可能となり、実務上大变好都合である.

謝辞：本研究で用いた全てのデー夕は北海道開発局より提供 を受けたものである。関係各位に謝意を表する。

参考文献

1）清水康行, 䂽峨浩, 早川博, 品川守: 石狩川の土砂流出に関す 研究, 水工学論文集, 第42巻, pp. 1039-1043, 1998

2）渡邊清隆, 清水康行: 石狩川の土砂流出に関する研究, 土木 学会第53回年次学術講演会, pp. 502-503, 1998

3）石狩川物質輸送量観測資料：(財) 北海道河川防災研究七ン 夕ー, 1997.

4）「石狩川流域土砂管理計画検討会」資料：(財) 北海道河川 防災研究七ンター, 1998

5）清水康行：沖積河川の維断形と河床材料分布形の形成につ いて,土木学会論文集№. 521/II -32, 69-78, 1995.8

6）清水康行, 板倉忠興, 岸力, 黒木幹男, : 昭和 56 年 8 月洪 水に おける石狩川の下流部の河床变動について, 第30回水理講演会 論文集, pp. 487-492, 1986

(1998. 9.30受付) 